\title{
The Research on Coupling Synergy and Influencing Factors of Technological Innovation and Standardization
}

\author{
Huan Chen* \\ School of Economics and Management \\ China Jiliang University \\ Hangzhou, China \\ 2657050185@qq.com
}

\author{
Yi-bing Tang \\ School of Economics and Management \\ China Jiliang University \\ Hangzhou, China \\ tangyangtony@163.com
}

\begin{abstract}
In order to give full play to the important role of standardization in innovation-driven development, and promote the high-quality development of China's national technical standard innovation base, it is of great significance to further clarify the coupling synergy between technological innovation and standardization and the influencing factors of them. By constructing the coupling synergy model between technological innovation and standardization, the coupling degree and coupling coordination degree of two systems from 2006 to 2015 were measured. Secondly, the grey correlation method is used to select the main factors affecting the interaction between China's two systems. The results show that the level of technical innovation and standardization and system coupling coordination degree as a whole is on the rise, and the coupling and coordinated development stage of the two also evolve from the initial serious imbalance to the moderate coordinated development. The main factors that affect the interaction between the two include the standard development contribution index, the technology market turnover, authorized invention patents, sales revenue of new products, the number of national standards and industry standards.
\end{abstract}

Keywords — technological innovation; standardization; coupling synergy; grey correlation method

\section{INTRODUCTION}

In today's world, the division of labor of value chain makes the relationship between standardization and innovation closer and closer, and the interaction and influence between them are more and more significant. In the Outline of the National Innovation-Driven Development Strategy, it is clearly proposed to implement the standardization strategy and further improve the interactive support mechanism for technological innovation and standardization. In order to promote the implementation of the State Council's national standardization work, China will build 50 national technology standard innovation bases during the 13th Five-Year Plan period. The establishment of technical standard innovation base requires the effective integration of resources in standards, technologies, talents, information, etc., and clarifies the relationship between the two systems of standardization and technological

Funded project: national natural science foundation of China "research on the benefits of knowledge collaboration and standard implementation of technical standards alliance: a perspective of network structure characteristics" (71603246) innovation, and explores the relationship between specific elements in the two systems. We should allocate resources reasonably, make up for our weak links in development, and provide reference for the increasingly integrated development of technological innovation and standardization, as well as the construction of national technological innovation bases.

There are three different views on the relationship between technological innovation and standardization. First, standardization promotes technological innovation. By accelerating the diffusion of technology and restricting the diversity of technology, production cost and transaction cost are reduced[1], thus improving the benefits of technological innovation. Second, standardization limits technological innovation, and standardization has a locking effect on technology. The evolution of the QWERTY keyboard fully illustrates this point[2]. Third, the relationship between standardization and technological innovation is uncertain, that is, standardization may promote technological innovation or hinder technological innovation[3]. In the recent study, Jiang[4] used the theory of binary eutectic alloy solidification to theoretically analyze technological innovation and standardization, revealing the internal mechanism of the two, and believed that technological innovation and standardization play an important role in improving the competitiveness of enterprises. Zoo[5] studied the relationship between innovation and standardization in the context of developing countries, and found that the promotion effect of standards on innovation was mainly manifested in three aspects: scale innovation, proof innovation and collaborative innovation. From the micro level, Blind[6] studied the impact of German manufacturing enterprises' innovation activities and their participation in national standardization on the signing of domestic procurement competition contracts and found that product innovation success and standardization were significant influencing factors for the success of enterprise public procurement.

Domestic scholars' research on the relationship between technological innovation and standardization, the mainstream view of technology standardization on the impact of technological innovation is a "double-edged sword". At the micro-enterprise level, Pan Xixi[7] used 277 listed companies 
TABLE I. TECHNICAL INNOVATION AND STANDARDIZATION SYSTEM INDICATORS industries in promoting technological innovation. Generally, the promotion of traditional industries was small, and the role of non-export enterprises was greater than that of export enterprises. At the meso-industrial level, Tao Zhongyuan[8] used BP neural network to analyze the impact of technological innovation and standardization on the international competitiveness of China's home appliance industry. At the national and regional levels, Hou Junjun[9] used provincial panel data, and empirical tests showed that standardization inputs have a significant role in promoting technological innovation, but the role at the national level is higher than the regional level. Zhan Ailan[10] studied the interactive catching up practice of standards and innovation in India and South Africa, and provided theoretical support and beneficial reference for the improvement of innovation and standardization ability under the coordination of various subjects in China.

\section{RESEARCH DESIGN}

\section{A. Indicator System}

In the existing research, the evaluation index system of technological innovation is relatively mature, and the index is often selected from two dimensions of input and output. This paper constructs the evaluation system of technological innovation from two aspects of input and output. Input includes human, financial and material input, which is the basis of technological innovation. Therefore, the total amount of $R \& D$ personnel, R\&D expenditures, new product development funds, and R\&D institutions were selected as input indicators. Outputs include direct and indirect outputs. The benefits of technological innovation are divided into two parts, one is the benefits obtained through patents, and the other is the benefits obtained through market transactions. Among the three types of patents, invention patents are more valuable for technological innovation, while authorized invention patents can directly reflect their output value. Therefore, the indirect output effect of technological innovation is measured by the technical market turnover and the sales revenue of new products.

Similarly, the standardization system is divided into input and output subsystems. Since it is difficult to obtain relevant data about the number of standardization practitioners and R\&D expenditure, the number of drafting units of national standards and industry standards and standardization management fees are used to measure the human and financial input of standardization respectively. The number of national standards and industrial standards represents the standardized output at the national level, and the number of participating international standards represents the internationalization level of China's standards. The contribution index of standard development proposed by Chinese institute of standardization is used to represent the output effect of standard development. Therefore, standardized output is expressed by the number of national standards and industry standards, the number of formulated international standards, and the standard development contribution index. The index system of technical innovation and standardization system is shown in table 1.

\begin{tabular}{|c|c|}
\hline Level indicators & Secondary indicators \\
\hline $\begin{array}{c}\text { Technology } \\
\text { Innovation } \\
\text { Input }\end{array}$ & R\&D expenditures(X1) \\
& New product development funds(X2) \\
R\&D institutions(X3) \\
Total amount of R\&D personnel(X4) \\
\hline $\begin{array}{c}\text { Technology } \\
\text { Innovation } \\
\text { Output }\end{array}$ & Authorized invention patents(X5) \\
Sales revenue of new products(X6) \\
Technical market turnover(X7) \\
\hline Standardized \\
Input & Standardization management fee(Y1) \\
& The number of drafting units(Y2) \\
\hline Standardized & The number of national standards and industrial \\
Output & standards (Y3) \\
& The number of participating international standards \\
& (Y4) \\
& The standard development contribution index(Y5) \\
\hline
\end{tabular}

\section{B. Data selection and weight calculation}

The data is selected from the relevant index of technological innovation and standardization during the " 11 th Five-Year Plan" and "12th Five-Year Plan” period from 2006 to 2015. The data of technical innovation is derived from the China Statistical Yearbook, and part of the standardized data comes from the national standard information public service platform and the website of China institute of standardization. Among them, the standardization management fee comes from the final report of the State Administration of Quality Supervision and Inspection. The number of international standards that China participates in the formulation comes from the data collected and collated by the official websites of ISO and IEC. The data is normalized by the range method, and the weight of the system index is calculated by the entropy weight method. The calculated index weights of technological innovation level and standardization level are shown in table 2

TABLE II. INDEX WEIGHT OF TECHNOLOGICAL INNOVATION LEVEL

\begin{tabular}{|c|c|c|c|c|c|c|c|}
\hline index & $\mathrm{X} 1$ & $\mathrm{X} 2$ & X3 & $\mathrm{X} 4$ & X5 & X6 & $\mathrm{X} 7$ \\
\hline weight & 0.127 & 0.153 & 0.174 & 0.107 & 0.138 & 0.147 & 0.153 \\
\hline \multicolumn{2}{|c|}{ TABLE III. } & \multicolumn{6}{|c|}{ INDEX WEIGHTS AT THE STANDARDIZED LEVEL } \\
\hline index & Y1 & & Y2 & Y3 & & & Y5 \\
\hline weight & 0.276 & & 0.182 & 0.178 & & & 0.154 \\
\hline
\end{tabular}

\section{THE EMPIRICAL RESEARCH}

\section{A. Coupled synergy model}

The coupling synergy in this paper is the interaction and influence between technology innovation and standardization. Set $\mathrm{U}_{1}$ as the order parameter of the technological innovation system, $U_{2}$ as the order parameter of the standardized system. Let $u_{i j}(\mathrm{i}=1,2 ; \mathrm{j}=1,2,3, \ldots, \mathrm{m})$ as basic observation index. $\lambda_{i j}$ is and table 3 . 
TABLE IV. COUPLING COORDINATION DEGREE AND COUPLING COORDINATION STAGE OF TWO SYSTEMS

the weight for each indicator, $U_{i}=\sum_{j=1}^{\mathrm{m}} \lambda_{i j} u_{i j}$ represents external development power function of two systems.

In order to solve the problem that both $U_{1}$ and $U_{2}$ have low values, but their coupling degree is very large, the model is further optimized and the coupling coordination degree model of both is constructed as follows:

$$
\left\{\begin{array}{l}
D_{t}=\sqrt{C_{t} T} \\
C_{t}=2\left(\frac{U_{1} U_{2}}{\left(U_{1}+U_{2}\right)}\right)^{\frac{1}{2}} \\
T=\alpha * U_{1}+\beta * U_{2}
\end{array}\right.
$$

In the above equation, $D_{t}$ represents the coupling coordination degree of the two systems, and $\mathrm{T}$ represents the coordination index of the two systems, reflecting the collaborative contribution between them. Generally, let $\alpha=\beta=0.5$, the two subsystems are equally important.

\section{B. Coupling synergy result}

The normalized data and weights were put into the efficiency function and coupling coordination model to calculate the efficiency values of the two subsystems of China's technological innovation and standardization from 2006 to 2015, as well as their coupling degree and coupling coordination degree. The trend of order parameter, coupling degree and coupling coordination degree of technological innovation and standardization subsystem are shown in Fig. 1. The coupling coordination degree and coupling coordination stage of the two systems are shown in Table 4.

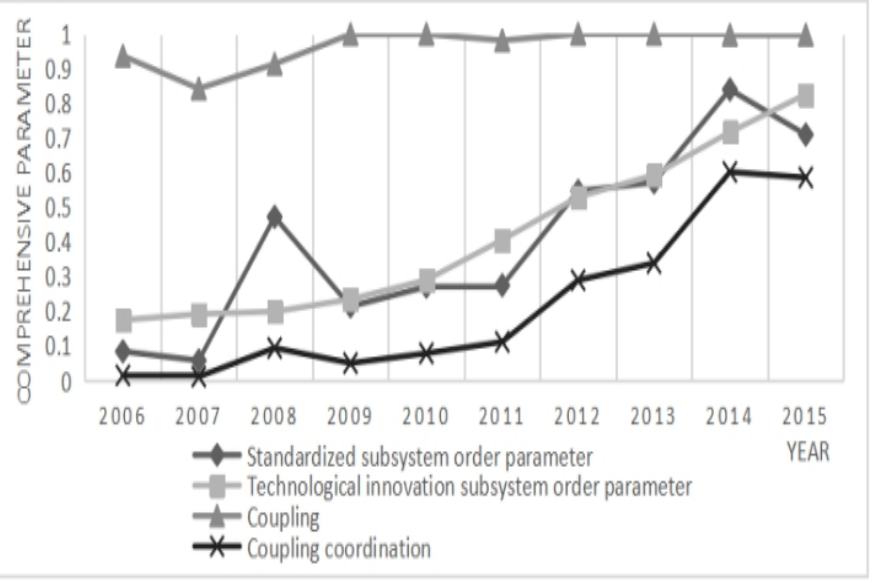

Fig.1. Trend diagram of coupling synergy between the two systems

As can be seen from the figure, the overall level of technological innovation in China is on the rise, from 0.174 in 2006 to 0.826 in 2015. During the eleventh five-year plan period (2006-2010), the growth rate of technological innovation was relatively slow, but during the twelfth five-year plan period, the growth rate was relatively fast. From 2006 to 2015, China's standardization level has basically increased, and the growth rate accelerated in 2008, 2012 and 2014.

\begin{tabular}{ccc} 
& \multicolumn{2}{c}{ COORDINATION STAGE OF TWO SYSTEMS } \\
\hline Year & $\begin{array}{c}\text { Coupling coordination } \\
\text { Degree }\end{array}$ & Coupling coordination stage \\
\hline 2006 & 0.112 & Serious disorder \\
2007 & 0.094 & Serious disorder \\
2008 & 0.331 & Moderate disorders \\
2009 & 0.222 & Moderate disorders \\
2010 & 0.278 & Moderate disorders \\
2011 & 0.321 & Moderate disorders \\
2012 & 0.54 & On the verge of disorder \\
2013 & 0.58 & On the verge of disorder \\
2014 & 0.788 & Moderate coordination \\
2015 & 0.754 & Moderate coordination \\
\hline
\end{tabular}

Although the degree of coupling and coordination between technological innovation and standardization in China is generally on the rise, it is more volatile during the period from 2007 to 2009, mainly because the comprehensive parameters of the standardized system are faster than the technological innovation; from 2009 to 2011, the degree of coupling coordination increased slowly. From 2011 to 2014, the degree of coupling coordination increased significantly. The slight decrease in 2015 was mainly due to the fact that the comprehensive parameters of the technology innovation system grew faster than the standardization, but the coupling and coordination degree of the two remained at a high level. The development stage of coupling coordination has experienced the evolution of severe disorder-moderate imbalance-onset-tomoderate coordination. This shows that China's technological innovation and standardization have passed the integration

\section{Gray correlation method}

The gray correlation method is used to further select the most important factors in the interaction between the two subsystems of technological innovation and standardization, and then make recommendations for high-quality economic development. Firstly, the basic indicators of standardization and technological innovation are analyzed as follows:

$$
\xi_{i}(j)=\frac{\min _{i} \min _{j}\left|Z_{i}^{X}-Z_{\mathrm{j}}^{Y}\right|+\rho \max _{i} \max _{j}\left|Z_{i}^{X}-Z_{j}^{Y}\right|}{\left|Z_{i}^{X}-Z_{\mathrm{j}}^{Y}\right|+\rho \max _{i} \max _{j}\left|Z_{i}^{X}-Z_{j}^{Y}\right|}
$$

$Z_{i}^{X}, Z_{\mathrm{j}}^{Y}$ respectively represent the standardized value of standardization and technological innovation index, and $\rho$ is the resolution coefficient, which is generally $0.5 . \xi_{i}(j)$ represents the correlation coefficient between the two indicators.

By averaging the correlation coefficients, an $\mathrm{m} \times \mathrm{l}$ correlation degree matrix can be obtained. According to $\gamma_{i j}$, the degree of relevance or coupling between standardization and technological innovation can be judged. Where period and entered the stage of coordinated development. 
China is on the rise, and the coupling coordination degree of $\gamma_{i j}=\frac{1}{k} \sum_{i=1}^{k} \xi_{i}(j), \mathrm{k}$ is $1,2, \ldots, \mathrm{n}$; $\mathrm{k}$ is the number of samples. the two systems is on the rise. From the perspective of the coupling development stage, the two evolved from the initial serious imbalance development to the moderate coordinated development stage. From the perspective of influencing factors, the main factors that affect the interaction between the two include the standard development contribution index, the technology market turnover, authorized invention patents, sales revenue of new products, the number of national standards and industry standards.

Therefore, our country should increase investment in standardization management fees, improve the quality of standard development; Improve the content of technical standards in products, promote the diffusion of standards; Establish a mechanism for the co-construction and sharing of science and technology and standardized resources, and promote the co-construction of science and technology and standardization experts; Scientific research institutions should establish a sense of technological standardization and compete for the right to speak of international standards. According to the stage of coordinated development and the main influencing factors, corresponding measures are taken to rationally adjust the development speed of technological innovation and standardization, and finally promote the coordinated development of technological innovation and standardization in China.

\section{REFERENCES}

[1] Tassey G. Standardization in technology-based markets[J]. Research Policy, 2000,29(4): 587-602.

[2] David P A. Clio and the Economics of QWERTY[J].American Economic Review Proceedings, 1985, 75 (2) :332-338.

[3] Swann G M P, Lambert R. Why do standards enable and constrain innovation [R]. Nottingham: Nottingham University Business School, 2010(7):1-20.

[4] Jiang H. Exploring the mechanism of technology standardization and innovation using the solidification theory of binary eutectic alloy[J].Technological Forecasting \&Social change,2018,135:217-228.

[5] Zoo H. Interplay of innovation and standardization: Exploring the relevance in developing countries [J]. Technological Forecasting \& Social change, 2017, 118:334-348.

[6] Blind K, Pohlisch J, Rainville A. Innovation and standardization as drivers of companies, success in public procurement: an empirical analysis [J/OL].The Journal of Technology Transfer. (2019-0220)[2019-09-26] .http://doi.org/10.1007/ s10961-019-09716-1.

[7] Pan Xixi. Empirical research on standardization and technological innovation based on data of listed companies [D]. Hunan University, 2016. (In Chinese)

[8] Tao Zhongyuan, Xue Chen. The impact of collaborative coupling of technological innovation and standardization on the international competitiveness of China's home appliance industry -- an empirical study based on BP neural network [J].Industrial technology economics,2016,35(09):146-154. (In Chinese)

\section{CONCLUSION}

In general, the coupling degree of China's technology innovation and standardization system has been at a high level of coupling, which indicates that China's technology innovation system and standardization system have a strong interaction. From the perspective of the coordinated development level, the overall level of technical innovation and standardization in

[9] Hou Junjun, Wang Juanjuan. An empirical study on region-based standardization and technological innovation [J]. Standard science,2014(08):11-16. (In Chinese)

[10] Zhan Ailan. Interactive catch-up model and path of standardization and innovation in emerging market countries: a case study of India and South Africa [J]. Science research management,2019,40(08):92-100. (In Chinese) 